\title{
Pseudomonas aeruginosa and cystic fibrosis: Antibiotic therapy and the science behind the magic
}

\author{
Noni E MacDonald MD MSc FRCPC
}

\begin{abstract}
NE MacDonald. Pseudomonas aeruginosa and cystic fibrosis: Antibiotic therapy and the science behind the magic. Can J Infect Dis 1997;8(6):335-342.

Respiratory failure secondary to chronic bronchiectasis is the cause of death in more than $90 \%$ of patients with cystic fibrosis (CF). The predominant microbes involved in CF lung disease are unusual: Pseudomonas aeruginosa, Staphylococcus aureus and Burkolderia cepacia. While antimicrobial therapy has been a component of CF care programs for decades, randomized controlled studies in the 1980s and early 1990s failed to show consistent measurable benefit. Research that stemmed from the discovery of the CF gene has shed new light on the inter-relationship of these microbes and the respiratory epithelial lung changes secondary to the $\mathrm{CF}$ gene. Five mechanisms have been proposed to explain the increased $P$ aeruginosa colonization of the lower airway in CF. Recent research has also shown that antimicrobial therapy in CF may be effective not through eradication of the organism but by decreasing bacterial density and exoproduct production in the lung and thus decreasing inflammatory stimulus; by protecting against the consequences of an overexhuberant host response and in patients with stop mutations, potentially by correcting the gene defect. This tale of misunderstanding of the role and value of antimicrobial therapy in $\mathrm{CF}$ care illustrates the importance of ensuring close communiation between clinicians and researchers. The randomized controlled studies of the 1980 s were not designed to answer the 'right' questions. The clinicians' observations that the CF patients did improve with antimicrobial therapy have been validated by recent studies using different endpoints.
\end{abstract}

Key Words: Antibiotic therapy, Cystic fibrosis, Pseudomonas aeruginosa

Pseudomonas aeruginosa et la mucoviscidose : Antibiothérapie et science font miracle

RÉSUMÉ : L'insuffisance respiratoire secondaire à la bronchiectasie chronique est la cause de décès chez plus de $90 \%$ des patients atteints de mucoviscidose (MV). Les principaux agents infectieux dans la maladie pulmonaire qui accompagne la MV sont inhabituels : Pseudomonas aeruginosa, Staphylococcus aureus et Burkolderia cepacia. Depuis des dizaines d'années on a recours à l'antibiothérapie dans la MV, mais des études contrôlées randomisées menées au cours des années 1980 et 1990 n'ont pu en confirmer un avantage mesurable. La recherche qui a suivi la découverte du gène de la MV a éclairé d'un jour nouveau l'interrelation entre les organismes pathogènes et les anomalies de l'épithélium pulmonaire associées au gène de la MV. Cinq mécanismes ont été proposés pour expliquer l'accroissement de la colonisation des voies respiratoires inférieures par $P$. aeruginosa dans la MV. De récentes recherches ont également démontré que

This paper was presented as the Canadian Infectious Disease Society Lecture 1996 in Halifax, Nova Scotia

Paediatrics, Microbiology and Immunology, University of Ottawa, and Division of Infectious Disease, Children's Hospital of Eastern Ontario, Ottawa, Ontario

Correspondence: Dr NE MacDonald, Division of Infectious Diseases, Children's Hospital of Eastern Ontario, Room 3035A, 401 Smyth Road, Ottawa, Ontario K1H 8L1.Telephone 613-737-2651,fax 613-738-4832, e-mail Macdonald_n@cheo.on.ca 
l'antibiothérapie pourrait être efficace dans le tableau, non pas par l'éradication de l'organisme pathogène, mais bien par une réduction de la densité bactérienne et de l'exoproduction dans les poumons, ce qui atténue le stimulus inflammatoire et protège l'individu contre les conséquences d'une réponse exagérée et chez les patients qui présentent une mutation de terminaison, en corrigeant peut-être l'anomalie génétique. Cet exemple d'incompréhension du rôle et de l'utilité de l'antibiothérapie dans la MV illustre l'importance d'une bonne communication entre cliniciens et chercheurs. Les études contrôlées randomisées des années 1980 ne répondaient pas à la bonne question. Les observations des cliniciens quant à l'amélioration de l'état des patients grâce à l'antibiothérapie ont été validées par de récentes études portant sur différents paramètres.

$\mathrm{C}_{\mathrm{s}}^{\mathrm{y}}$ ystic fibrosis (CF) is the most common serious disease among Caucasian children, affecting between one in 2000 and one in 4500 children $(1,2)$. While cystic fibrosis was thought to be a gastrointestinal disease when it was first described by Anderson in the late 1930s, it is now well recognized as a multisystem disorder, with lung involvement as the major cause of morbidity and mortality (2).

In addition to affecting the lungs, the disease also affects the upper respiratory tract, pancreas, hepatobiliary system, gastrointestinal tract, endocrine system, sweat glands and reproductive tract, seen as obstructive aspermia in men and thick cervical mucus in women (2).

From the genetic perspective, $\mathrm{CF}$ might well be labelled defective $\mathrm{CF}$ transmembrane conductance regulator (CFTR) syndrome (1). The gene responsible for $\mathrm{CF}$ is located on the long arm of chromosome 7 and contains 24 exons that encode the protein CFTR. CFTR is found in a variety of secretory epithelial cells, mostly localized to the apical membrane, and it functions as a chloride channel regulated by cAMP. Other intracellular functions are suspected but not yet well defined. For example, widespread reductions in the sialylation of secreted proteins and increases in the sulphation and fucosylation of mucus glycopeptides are found in patients with CF (3).

\section{DOUBTS ABOUT THE VALUE OF ANTIBIOTIC THERAPY IN CF CARE}

Antibiotic therapy to combat the lung infection has been part of CF care for decades (4). While clinicians caring for CF patients long recognized that pulmonary exacerbations responded to antibiotic therapy, study after study through the 1980 s and early 1990s could not consistently show a measurable improvement; this led some researchers to doubt the benefit of the antibiotic therapy. For example, in 1980, Beaudry et al (5) published a paper entitled, "Is anti-pseudomonas therapy warranted in acute respiratory exacerbations in children with cystic fibrosis?". In this randomized controlled trial, 22 children with severe $\mathrm{CF}$ and acute exacerbations received either intravenous cloxacillin or carbenicillin plus gentamicin for 10 days. Clinical improvement, chest radiograph changes, evidence of airway obstruction and bacteriological flora of sputum did not differ between the groups regardless of which regimen was used. Beaudry et al (5) interpreted these results to mean that antipseudomonas medication may not always be necessary for exacerbations.

Also in 1980, Wientzen et al (6), in a double-blind trial of tobramycin versus placebo for treatment of acute exacerbations, did not find any statistically significant clinical differ- ence in outcome between the two groups, although there was a trend to more improvement with tobramycin. Although not significant, it is noteworthy that six of the seven tobramycintreated patients showed a $1 \log$ decrease in Pseudomonas aeruginosa concentration in the sputum post-therapy compared with only two of eight treated with placebo.

In 1987, Gold et al (7) reported the outcome of a randomized trial of ceftazidime versus placebo in the management of acute respiratory exacerbations in $\mathrm{CF}$ patients with mild to moderate disease. A number of outcome criteria, including symptom score, weight gain, pulmonary function and quantitative sputum cultures, was assessed. While there was a trend to a quantitative decrease in the concentration of $P$ aeruginosa in the sputum cultures in the group receiving ceftazidime, there was no significant difference compared with the placebo group either at discharge or on follow-up six to 24 months later. These authors concluded that intravenous antibiotic therapy was not essential in the management of all acute respiratory exacerbations in patients with mild to moderate $\mathrm{CF}(7)$.

Much of the research on antibiotic use in CF patients during the 1980 s was devoted to furthering the understanding of antibiotic kinetics in this patient population (8-10). There was also growing recognition that treatment in hospital might have negative consequences, such as increasing the risk of acquiring Burkholderia cepacia, a multiresistant organism that can cause severe deterioration in some CF patients (11). Some $\mathrm{CF}$ centres also became concerned that centralized $\mathrm{CF}$ care and the use of antibiotics may increase the risk of $P$ aeruginosa infection (12). Thus, the question kept recurring - were antibiotics regimens useful in CF care or were they just a 'tradition of practice', like mist tents in the 1950s and 1960s until the tents were shown not to be helpful (13). Despite the controversy, cli-

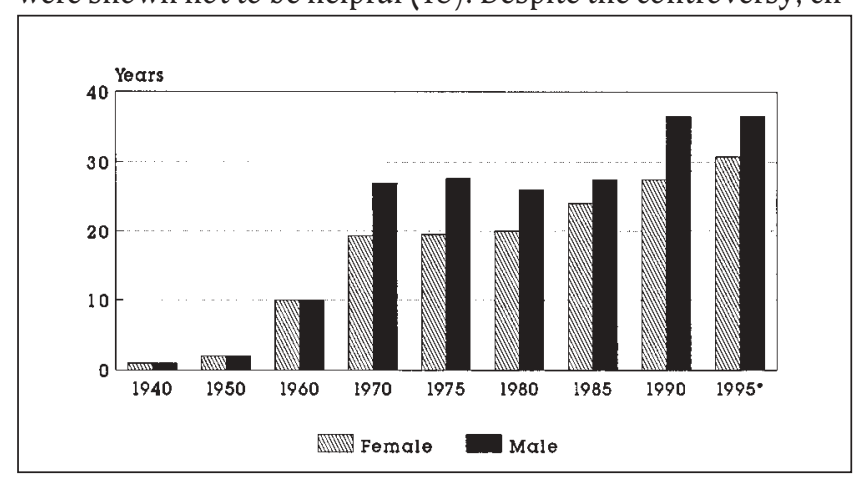

Figure 1) Median survival in years of cystic fibrosis patients in Canada by decade. Data supplied by the Canadian Cystic Fibrosis Foundation Registry 1996 
TABLE 1

Comparison of bronchiectasis in cystic fibrosis (CF), immotile cilia syndrome (ICS) and X-linked agammaglobulinemia (X-LA)

\begin{tabular}{lccc}
\hline Pathology & CF & ICS & XLA \\
\hline Area of lungs where more severe & Upper lobes & Various & Various \\
Histology & Similar & Similar & Similar \\
Age at first changes & Younger than four months & Late infancy & Older than one year \\
Percentage changes at young age & +++ & $+/-$ & $+/-$ \\
Microbiology & Staphylococcus aureus & Haemophilus influenzae & H influenzae \\
& H influenzae & Streptococcus viridans & S aureus \\
Immunoglobulin G & Pseudomonas aeruginosa & Neisseria species & Streptococcus pneumoniae \\
Rate of progression & Increase & $\mathrm{N}$ & Decrease \\
\hline
\end{tabular}

+++ Large increase; +/- Little or no change

nicians at the bedside and patients remained adamant in their belief that patients were better when antibiotics were included in the therapy of exacerbations even if researchers could not show a benefit.

\section{IMPROVED CF SURVIVAL}

During the 1970 s and 1980 s, care by CF clinicians was leading to a marked increase in survival. Median ages of survival of $\mathrm{CF}$ patients in Canada over the past four decades are presented in Figure 1. Median survival age tripled between 1960 and 1990 from 10 to 30 years. The median age of CF patients has increased such that $\mathrm{CF}$ is now an adult disease. Close to $40 \%$ of all CF patients in Canada are 18 years of age or older.

\section{CF LUNG DISEASE AND HOW IT DIFFERS FROM THAT FOUND IN OTHER CHILDHOOD CAUSES OF BRONCHIECTASIS}

The bronchiectasis seen in CF does not differ from that seen in immotile cilia syndrome or X-linked agammaglobulinemia (X-LA) in terms of histology, but it does differ in a number of other important areas (Table 1). Bronchiectasis in all three conditions is thought to result from a combination of obstruction with infection and the inflammatory response to infection (14). This leads to progressive damage to the supportive structure of the bronchial wall, leading to bronchiectasis. Two classic animal models have shown that the combination of obstruction with infection and inflammation must be present for damage to occur $(15,16)$.

When the clinical course of $\mathrm{CF}$ bronchiectasis is compared with that seen in the other two conditions, there are similarities and differences. In all three conditions, the lungs are normal at birth. Bronchiectasis starts after birth and progresses over time. The area of lung most severely involved in CF initially is usually the upper lobes. In contrast, in immotile cilia syndrome and X-LA, the area of initial involvement is variable.

The lung changes in CF start at a very early age. Autopsy data from 82 patients aged five days to 24 years evaluated by Bedrossian et al (17) revealed that mucus plugging was relatively common, and bronchiectasis could already be seen in $20 \%$ of infants who died at less than four months of age. By two years of age, $75 \%$ had evidence of bronchiectasis. While
TABLE 2

Proposed mechanisms for increased Pseudomonas aeruginosa colonization of the lower airway in cystic fibrosis (CF) patients

Increased adherence of $P$ aeruginosa to CF respiratory epithelial cells

Increased adherence/decreased destruction of $P$ aeruginosa in mucin in CF lungs

Decreased mucociliary clearance of $P$ aeruginosa and mucus in CF lungs

Decreased internalization of $P$ aeruginosa by CF epithelial cells Decreased phagocytosis of $P$ aeruginosa by pulmonary alveolar macrophages

one may argue that this is an old study (1976), more recent ultrafast computed tomography (CT) studies of the lungs of CF patients also suggest that bronchiectasis starts early and may be present even in young children with $\mathrm{CF}$ who have normal chest X-rays. A study by Nathanson and colleagues (18) found abnormalities by ultrafast CT lung scores in $88 \%$ of 25 children, despite relatively normal chest x-rays in 21 of 25 . The average age of these patients was only four years.

The microbial lung invaders in $\mathrm{CF}$ also differ considerably from those seen in the other two childhood bronchiectatic conditions. While $P$ aeruginosa is the dominant pathogen in $\mathrm{CF}$, it is an unusual pulmonary isolate to find in the other two conditions where more 'usual' upper respiratory organisms such as Haemophilus influenzae, Neisseria species and Streptococcus pneumoniae predominate.

Colonization with microbial pathogens begins early in $\mathrm{CF}$ patients. Culture of bronchial alveolar lavage fluid from 45 young CF infants (mean age 2.6 months) in a 1995 Australian study found that 14 were already colonized with Staphylococcus aureus and two with $H$ influenzae (19). Inflammatory changes were already present in those who already had microbes in their lower airways. Kahn et al (20) has shown that inflammatory changes may even be present in CF infants less than four weeks of age. The predominant microbial pathogens in CF shifts from $S$ aureus and H influenzae to P aeruginosa by school age $(21,22)$. 


\section{WHY IS P AERUGINOSA SUCH A COMMON PATHOGEN IN CF?}

Five pathogenic mechanisms have been proposed to explain the increased $P$ aeruginosa colonization of the lower airway of CF patients (Table 2).

Increased adherence of $\boldsymbol{P}$ aeruginosa to CF respiratory epithelial cells: Adherence of bacteria to specific cellular receptors is the initial event in many infectious diseases. Kriven et al (23) reported that $P$ aeruginosa recognizes the Gal Nac B1-4 Gal sequence present on glycosphingolipids asialo GM1, asialo GM2, asialo CAD and related glycolipids but not to their sialated homologues GM1 and GM2. Saiman and Prince (24) went on to show that respiratory epithelial cells from CF patients have more asialo GM1 than do respiratory epithelial cells from non-CF patients. Undersialation of mucus glycoproteins in $\mathrm{CF}$ clinical specimens was recognized early in the 1980 s, but its significance was not understood at that time (25). Prince and colleagues have proposed that the loss of the CFTR chloride channel from intracellular glycosialation compartments in CF patients leads to a decrease in sialtransferase activity which results in defective sialation of the gangliosides on the CF respiratory epithelial cells and an increase in $P$ aeruginosa binding sites.

Differences in sialation as a consequence of changes in acidification may be present in various cell types. While a general defect in endosomal acidification as a consequence of CFTR is unlikely, a relative difference in expression of CFTR in different populations of cell types and in discrete subcellular compartments may be responsible for altered local acidification and, thus, sialation. Such defective acidification of intracellular organelles has been reported in CF (26). The CF epithelia undersialate only the apically secreted proteins, while basolaterally secreted proteins are normally sialated (27). Wild type CFTR traverses an apical sialation compartment en route to the apical plasma membrane, whereas it is absent from apical organelles in CF cells. These asialated glycolipids then serve as the receptors for the pseudomonas pilus on the surface of these CF respiratory epithelial cells and preferentially allow it to bind. Furthermore, there is increased production of neuraminidase by $P$ aeruginosa under the hyperosmolar conditions seen in CF mucus (28). Neuraminidase, by clipping off sialic acid residues, acts to expose other previously sequestered pseudomonas binding sites. Thus, pseudomonas not only has an initial advantage for binding due to increased amount of asialated GM1 and GM2, but further increases its advantage by secreting neuraminadase which can uncover more sites.

Not only can $P$ aeruginosa bind effectively to the asialated GM1 sites, but $S$ aureus is also preferentially bound; this is not so for other Gram-negative organisms such as Escherichia coli (27). Anti-AGM1 inhibits binding of both $P$ aeruginosa and $S$ aureus in a dose dependent manner and reaches statistical significance at $3 \mu \mathrm{g} / \mathrm{mL}$, while control polyclonal antibody is ineffective (27). The complex sugar on AGM1, which is the specific binding receptor for both $P$ aeruginosa and $S$ aureus, is a tetrasaccharide.

Given that there are at least four mechanisms by which
CF-associated mutations disrupt CFTR function, several groups have tried to determine whether there is a correlation between the $\mathrm{CF}$ genetic determinant and airway colonization with $P$ aeruginosa. The four classes of $\mathrm{CF}$ genetic defects are (1) defective protein production, (2) defective processing, (3) defective regulation and (4) defective conduction (29). The most common mutation, F508, is a class 2 defect, ie, defective processing. Zar et al (30) have shown that adherence of $P$ aeruginosa to respiratory epithelium can be correlated with homozygosity to F508. Kubesch and colleagues (31) observed that the age specific colonization rates with $P$ aeruginosa are quite different between $\mathrm{CF}$ patients who are pancreatic insufficient (double F508 or a F508 heterozygote) and pancreatic sufficient patients. Pancreatic sufficient patients are more likely to have missence or spliced mutations where no CFTR is produced (31). The lack of production of CFTR in these patients would not lead to increased acidification in the intracellular organelles; sialation of GM1 would occur normally and thus there would be no specific binding sites for pili of $P$ aeruginosa.

Increased adherence or decreased destruction of $P$ aeruginosa in mucin in CF lungs: The pathogenesis of an infection in $\mathrm{CF}$ has long been attributed to interactions between the viscous CF mucin and $P$ aeruginosa. Ramphal and Pyle (32) presented data, which suggested that heavily glycosylated mucin glycoproteins were receptors for $P$ aeruginosa. However, more recent studies have failed to identify specific receptors for $P$ aeruginosa in mucin and further suggest that this binding is nonspecific $(33,34)$.

The impaired serous secretion and abnormal mucus production in CF may, however, impair normal host defence against $P$ aeruginosa. Recently, Smith and colleagues (35) have provided preliminary support for this theory by showing that $P$ aeruginosa is killed when it is added to the apical surface by normal airway epithelia cells in culture but multiplies when added to CF epithelia in culture. This bactericidal activity is present in the airway surface fluid of both normal and CF cells. However, for bacterial killing, a low sodium chloride concentration is required. In vivo, CF surface fluid is high in sodium chloride and fails to kill $P$ aeruginosa. The bactericidal factors are thought to be cationic peptides, which are naturally secreted antimicrobials that are secreted by epithelial cells and are active at low but not high salt concentrations.

Decreased mucociliary clearance of $\boldsymbol{P}$ aeruginosa: The third proposed pathogenic mechanism involves decreased mucociliary clearance. Inspired air contains thousands of tiny particles of dust, airborne bacteria and viral agents which, if more than $2 \mu \mathrm{m}$ in diameter, may enter the small airways and sediment out on the airway wall surfaces. This debris is usually swept back out of the lungs by the ciliated epithelial cells. For the cilia to clean the lung, the fluid layer must be thick enough to float the debris but thin enough not to obstruct the flow. When a particle sediments on the dry surface, it must first be mobilized into the fluid layer to be cleared. The CFTR protein is thought to be critical for this process (36). Quinton (36) has postulated that the epithelial cells under the debris become irritated and respond by opening the CFTR chloride channel to secrete the 
TABLE 3

Actions of some Pseudomonas aeruginosa products on the immune system that may contribute to pathogenesis of cystic fibrosis lung disease

$\begin{array}{ll}\text { Mucoid exopolysaccharide } & \text { - Antiphagocytic } \\ & \text { - } \text { Chemotaxis inhibitor } \\ & \text { - Activates classical } \mathrm{C}^{1} \\ \text { Slime } & \text { Causes leukopenia } \\ & \text { - Mitogen for lymphocytes } \\ & \text { - Activates alternate } \mathrm{C}^{1} \\ \text { Exotoxin A } & \text { Inhibits protein synthesis } \\ & \text { - Toxic to macrophages } \\ \text { Proteases } & \text { Suppresses T cell function } \\ & \text { - Inactivate complement } \\ & \text { - Inactivate alpha1 protease } \\ & \text { inhibitor }\end{array}$

Modified from reference 38. $C^{1}$ Complement pathway

fluid needed to wash the debris away in the surface layer. Once the particle has been moved away, the remaining excess fluid is then reabsorbed, thus helping to propel the debris up and out of the airway in a continuous sequence of secretion of fluid in front of and around the particle and then reabsorbtion of the fluid behind, while cilia move the fluid-surrounded particle along. In $\mathrm{CF}$, the airway may not be able to respond rapidly or appropriately to the debris due to impaired acute secretion and possibly a defect in absorption $(36,37)$. This may cause the particle and mucus around it to become lodged in the airway, accelerate the onset of infection and stimulate an inflammatory response, leading to further obstruction of the airway and damage to the bronchiole wall.

A further problem with mucociliary clearance is the dyskinesis of the cilia themselves. The ciliary beat dysfunction is thought to be secondary to the presence of an inhibitory factor found in CF lung secretions and CF serum, the complement activation product of $\mathrm{C} 3 \mathrm{a}(38,39)$.

Decreased internalization of $\boldsymbol{P}$ aeruginosa by epithelial cells: The fourth postulated mechanism is decreased internalization of $P$ aeruginosa epithelial cells. Binding and internalization of pathogens by epithelial cells followed by desquamation is known to be an important defence mechanism for clearing bacteria in the bladder. A similar mechanism is postulated for protecting the lung. Pier and colleagues (40) have shown that cultured human airway epithelial cells expressing the F508 allele of CFTR are defective in their uptake of $P$ aeruginosa compared with cells expressing the wild type allele. CF cells internalize significantly fewer bacteria in a tissue culture model. The $P$ aeruginosa ligand for epithelial cell ingestion was determined to be the lipopolysaccharide-core oligosaccharide. The effect of F508 CFTR appears to be specific for $P$ aeruginosa. Other bacteria such as E coli, B cepacia, Neisseria mengingitidis, $S$ aureus and $S$ pneumoniae were equally well internalized by the wild strain and the F508 CFTR cell lines. A concern with this study is that the assay used to assess bacterial killing by the epithelial cells measured viable bacteria

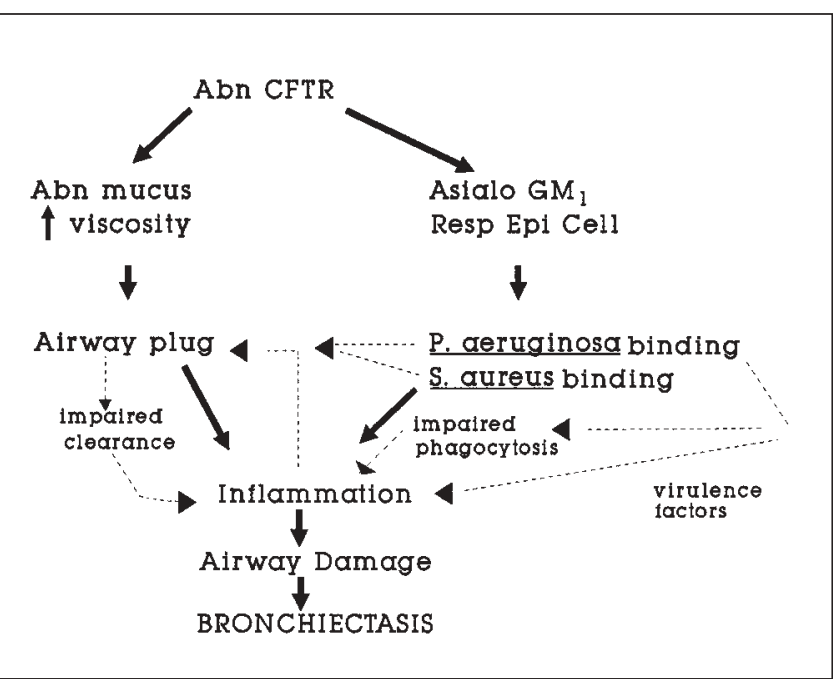

Figure 2) Model of bronchiectasis cascade. Abn Abnormal; CFTR Cystic fibrosis transmembrane conductance regulator; $\mathrm{P}$ aeruginosa Pseudomonas aeruginosa; S aureus Staphylococcus aureus

following gentamicin killing of noningested bacteria (41). Given the sensitivity and specificity of this type of bioassay, there is concern that the results reported may have over- or underestimated epithelial cell ingestion of $P$ aeruginosa.

Decreased phagocytosis of $P$ aeruginosa by pulmonary alveolar macrophages: The fifth proposed pathogenic mechanism for increased $P$ aeruginosa lung colonization in $\mathrm{CF}$ patients is impaired phagocytosis by pulmonary alveolar macrophages and neutrophils. Phagocytosis plays an important role in host defence against bacterial infection in the lung. Both neutrophils and alveolar macrophages are capable of ingesting $P$ aeruginosa in vitro (38). Alveolar macrophage function, however, may be compromised in vivo. Alveoli lack glucose, a critical factor for $P$ aeruginosa ingestion by macrophages. Barghouthi et al (42) have shown that inhibitors of glucose transport suppress ingestion of $P$ aeruginosa but not zymosan, a particle that is phagocytozed in the absence of glucose. This could lead to impaired $P$ aeruginosa phagocytosis by alveolar macrophages in $\mathrm{CF}$ patients in vivo.

A further problem is the poor killing of $P$ aeruginosa by serum in CF patients. The majority of CF $P$ aeruginosa isolates are serum sensitive and are easily killed by normal human serum via the classical or alternate complement pathway. Because CF lung secretions are rich in inflammatory exudates, the expectation is that there are sufficient quantities of complement and immunoglobulin (Ig) in these secretions to kill these exquisitely serum-sensitive isolates. However, that does not occur. Several groups of investigators have identified a blocking factor, fragmented IgG, in the sputum of some CF patients (38). The fragments are cleavage products resulting from the action of neutrophil or bacterial proteases. The FAB IgG fragment binds to $P$ aeruginosa but lacks the FC component to attach the macrophage receptor site. This results in further blocking of macrophage and neutrophils phagocytosis and enhances survival of the serum-sensitive $P$ aeruginosa isolates. 


\section{VIRULENCE FACTORS OF P AERUGINOSA AND EFFECT ON THE HOST}

$P$ aeruginosa is a remarkably adaptive organism that produces many cellular and extracellular products that may contribute to the pathogenesis of pulmonary disease in $\mathrm{CF}$ patients (38). Some of the factors that impinge on the immune system are listed in Table 3 . The presence of $P$ aeruginosa in the lung and release of many of its products leads to ongoing stimulation of the immune system with an influx of neutrophils, release of cytokines and increased local inflammation.

\section{OVERVIEW OF INTERACTION OF MULTIPLE FACTORS IN THE PATHOGENESIS OF CF LUNG DISEASE}

The abnormal CFTR gene in CF patients increases the ability of $P$ aeruginosa to attach to the respiratory epithelium because of increased asialo GM1 (Figure 2). The gene abnormality also causes impairment of normal host defence mechanisms with poor mucociliary clearance due to increased viscosity of the mucus, and decreased bacterial action of the alveolar fluid due to loss of function of the naturally secreted cationic peptides in a high salt environment. This leads to blocking of the terminal bronchioles and small bronchi with bacteria and mucus, and a marked inflammatory reaction. Impaired phagocytosis and killing of the $P$ aeruginosa by neutrophils and macrophages leads to self-destruction of the neutrophils, with release of enzymes such as elastase and myeloperoxidase that act either directly or indirectly to damage the bronchiole airway walls and lead to bronchiectasis and lung damage.

\section{DOES ANTIBIOTIC THERAPY AFFECT THE CF BRONCHIECTASIS CASCADE?}

Four possible benefits of antibiotic therapy in CF patients have been postulated (Figure 3). Regelmann et al (43) have shown that 14 days of parenteral tobramycin and ticarcillin therapy for an acute pulmonary exacerbation is associated with a significant decrease in the bacterial density in CF sputum compared with placebo. Grimwood and colleagues (44) have found increased concentrations of $P$ aeruginosa virulence factors such as exoenzyme A during pulmonary exacerbations, which decrease with antibiotic therapy. Furthermore, even subinhibitory concentrations of antibiotics, such as ciprofloxacin, ceftazidime and tobramycin, lead to a decrease in $P$ aeruginosa exoproduct production $(45,46)$. The decrease in bacterial load and decrease in virulence factors leads to a decrease in the inflammatory stimulus and, thus, a slowing in the damage to the walls of the bronchioles.

Antibiotic therapy may also help to protect against the consequences of an overexuberant host response. Cantin and Woods (47) have postulated that aminoglycosides, such as tobramycin and gentamicin which bind to anionic cell surfaces because they are cations, may help to block the negative consequences of myeloperoxidase release from the self-destructing frustrated neutrophils (47). Instead of the myeloperoxidase acting to convert chloride into toxic hypochlorous acid in the presence of hydrogen peroxide, it is converted to noncytotoxic chloramines. Furthermore, penicillins and cephalospor-

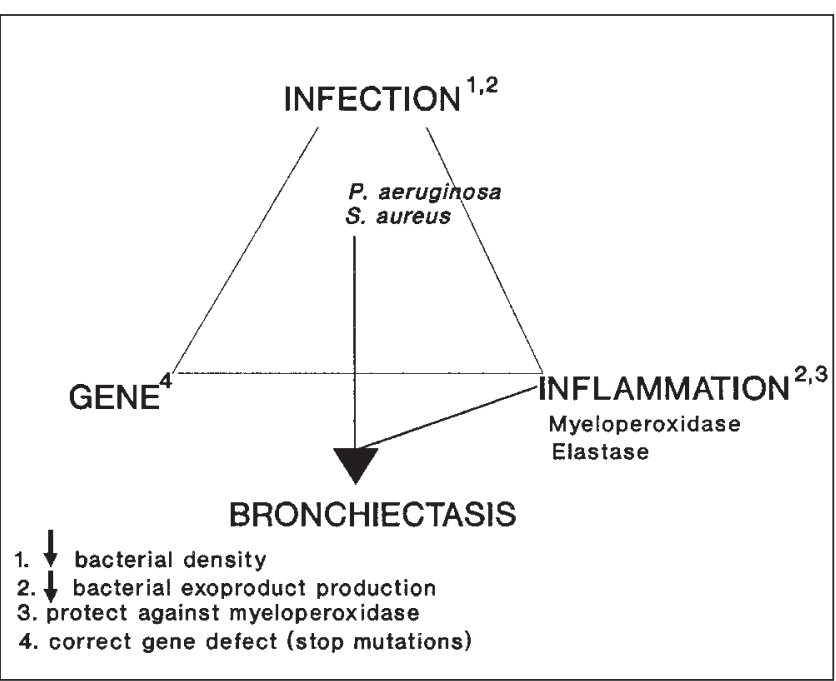

Figure 3) Possible actions of antibiotic therapy in slowing the bronchiectasis casade in cystic fibrosis patients. P aeruginosa Pseudomonas aeruginosa; $S$ aureus Staphylococcus aureus

ins are also potent hypochlorite anion scavengers that may help to protect critical extracellular molecules from oxidation.

The fourth possible function of antibiotics, particularly aminoglycosides, is truly remarkable - correcting the CFTR defect! Howard et al (48) have shown that low doses of aminoglycoside G418 changes CFTR production and function in the tissue culture of cells transfected with abnormal genes with the class 1 defect, ie, premature stop mutations. These class 1 defects occur in approximately $5 \%$ of $\mathrm{CF}$ patients. This group demonstrated that low dose treatment of the transfected cells with aminoglycoside G418 resulted in expression of full length CFTR and restored cyclic AMP-activated chloride channel activity. Gentamicin also promoted the expression of full length CFTR, albeit only in small amounts. No full length CFTR was detected with tobramycin treatment but this may in part be due to the insensitivity of the assay (48).

Given this increased understanding of the pathophysiology of bronchiectasis in $\mathrm{CF}$, it is now clear that antibiotic therapy, as clinicians and patients have long known, does play an important role in modifying the cascade to lung disease. Not only does it decrease $P$ aeruginosa virulence factor production and sputum $P$ aeruginosa bacterial density, but also in a minor way it may offer some anti-inflammatory protection and, in a minority of patients, possibly help to overcome the underlying gene defect.

\section{COMMUNICATIONS: BENCH AND THE BEDSIDE}

This tale of woe of our misunderstanding of the benefit of antibiotics in CF patients and disbelief at the clinicians' bedside impression clearly illustrates the importance of ensuring clear communication between researchers and clinicians. If the message to researchers that antibiotic therapy did work had been clearer, maybe the 'right' questions would have been asked earlier and the basis for the multiple possible roles of antibiotic therapy in CF patients understood more quickly. This is an important lesson for clinical researchers; never dismiss a clinical observation because the science does not seem 
to fit. The questions being asked may be the wrong ones. This misunderstanding also highlights a concern with the current push for evidence-based medicine for all our practices. If the studies do not ask the right questions or use the correct outcome markers, 'good' treatments may be discarded prematurely. Based upon randomized control trials in the 1980s, antimicrobial therapy for CF pulmonary exacerbations would have been discarded. Only recently have the right questions been asked, and good evidence of the value of this therapy been shown.

These are indeed exciting times to be caring for CF patients. There has been tremendous improvement in survival and quality of life over the past two decades. As science moves forward to explain more of the magic behind our current CF pulmonary care programs $(49,50)$, further improvements at the bedside will occur. The ultimate goal is to have $\mathrm{CF}$ patients live anormal lifespan. By sharing with the infectious diseases community some of the science behind the magic of CF care, the hope is that infectious disease physicians will be just that much more curious when asked to see a CF patient in consultation because of a resistant organism. Perhaps this will also entice more infectious disease specialists to join the CF research and clinical care community.

ACKNOWLEDGEMENTS: The author thank Drs Nicole Le Saux, Francisco Diaz-Mitoma and Andre Cantin for their comments during the development of the manuscript; Ian McIntosh of the Canadian Cystic Fibrosis Foundation for providing the registry data; and the Canadian Infectious Disease Society and Dr Gary Garber for the opportunity to present the 1996 Canadian Infectious Disease Society Lecture.

\section{REFERENCES}

1. Tizzano EF, Buchwald M. Cystic fibrosis: Beyond the gene to therapy. J Pediatr 1992;120:337-49.

2. Colin AA, Wohl MEB. Cystic fibrosis. Pediatr Rev 1994:15:192-200.

3. Barasch J, Al-Awqati Q. Defective acidification of the biosynthetic pathway in cystic fibrosis. J Cell Sci 1993;S17:229-33.

4. MacDonald NE, Corey M, Morrison R. General approach to cystic fibrosis pulmonary infection: Canada. In: Marks M, ed. Cystic Fibrosis Pulmonary Infection - Lessons From Around the World. Basel: Birkhauser Verlag AG, 1996:111-7.

5. Beaudry PH, Marks MI, McDougall D, Desmond K, Rangel R. Is anti-pseudomonas therapy warranted in acute respiratory exacerbations in children with cystic fibrosis? J Pediatr 1980;97:144-7.

6. Wientzen R, Prestidge CB, Kramer RI, McCracken GH, Nelson JD. Acute pulmonary exacerbations in cystic fibrosis. A double-blind trial of tobramycin and placebo therapy. Am J Dis Child 1980;134:1134-8.

7. Gold R, Carpenter S, Heurter H, Corey M, Levison H. Randomized trial of ceftaxidime versus placebo in the management of acute respiratory exacerbations in patients with cystic fibrosis. J Pediatr 1987;111:907-13.

8. MacDonald NE, Anas NG, Peterson RG, Schwartz RH, Brooks JG, Powell KR. Renal clearance of gentamycin in cystic fibrosis. J Pediatr 1983;103:985-90.

9. Levy J, Smith AL, Koup JR, Williams-Warren J, Ramsey B. Disposition of tobramycin in patients with cystic fibrosis: A prospective controlled study. J Pediatr 1984;105:117-24.

10. Reed MD, Stern RC, Bertino JS, Myers CM, Yamashita TS, Blumer JL. Dosing implications of rapid elimination of trimethoprimsulfamethoxazole in patients with cystic fibrosis. J Pediatr 1984;104:303-7.

11. Goldmann DA, Klinger JD. Pseudomonas cepacia: Biology, mechanisms of virulence, epidemiology. J Pediatr 1986;108:806-12.
12. Pedersen SS, Jensen T, Pressler T, Hoiby N, Rosendal K. Does centralized treatment of cystic fibrosis increase the risk of Pseudomonas aeruginosa infection? Acta Paediatr Scand 1986;75:840-5.

13. Motoyama KE. Evaluation of mist tent therapy in cystic fibrosis using maximal expiratory flow-volume curves. Pediatr 1972;50:299-306.

14. Lewiston NJ. Bronchiectasis in childhood. Pediatr Clin North Am 1984:31:865-77.

15. Tannenberg J, Pinner MA. Atelectasis and bronchiectasis. An experimental study concerning their relationship. J Thorac Surg 1942;11:571-616.

16. Cheng K-K. The experimental production of bronchiectasis in rats. J Pathol Bacteriol 1954;57:89-98.

17. Bedrossian CWM, Greenberg SD, Singer DB, Hansen JJ, Rosenberg HS. The lung in cystic fibrosis. A quantitative study including prevalence of pathologic findings among different age groups. Hum Pathol 1976;7:195-204.

18. Nathanson I, Conboy K, Murphy S, Afshani E, Kuhn JP. Ultrafast computerized tomography of the chest in cystic fibrosis: A new scoring system. Pediatr Pulmonol 1991;11:81-6.

19. Armstrong DS, Grimwood K, Carzino R, Carlin JB, Olinsky A, Phelan PD. Lower respiratory infection and inflammation in infants with newly diagnosed cystic fibrosis. BMJ 1995;310:1571-2.

20. Khan TZ, Wagener JS, Bost T, Martinez J, Accurso FJ, Riches DWH. Early pulmonary inflammation in infants with cystic fibrosis. Am J Respir Crit Care Med 1995;151:1075-82.

21. Ramsey BW, Wentz KR, Smith AL, et al. Predictive value of oropharyngeal cultures for identifying lower airway bacteria in cystic fibrosis patients. Am Rev Respir Dis 1991;144:331-7.

22. FitzSimmons SC. The changing epidemiology of cystic fibrosis. I Pediatr 1993;122:1-9.

23. Krivan HC, Roberts DD, Ginsburg V. Many pulmonary pathogenic bacteria bind specifically to the carbohydrate sequence GalNAcB1-4Gal found in some glycolipids. Proc Natl Acad Sci USA 1988;85:6157-61.

24. Saiman L, Prince A. Pseudomonas aeruginosa pili bind to AsialoGM1 which is increased on the surface of cystic fibrosis epithelial cells. J Clin Invest 1993;92:1875-80.

25. Boat TF, Cheng PW. Biochemistry of airway mucus secretions. Fed Proc 1980;39:3067-74

26. Barasch J, Kiss B, Prince A, Saiman L, Guenert D, Al-Awqati O. Defective acidification of intracellular organelles in cystic fibrosis. Nature 1991;352:70-3.

27. Imundo L, Barasch J, Prince A, Al-Awqati Q. Cystic fibrosis epithelial cells have a receptor for pathogenic bacteria on their apical surface. Proc Natl Acad Sci USA 1995;92:3019-23.

28. Cacalano G, Kays M, Saiman L, Prince A. Production of the Pseudomonas aeruginosa neuraminidase is increased under hyperosmolar conditions and is required by genes involved in alginate expression. J Clin Invest 1992;89:1866-74.

29. Welsh MJ, Smith AE. Molecular mechanisms of CFTR chloride channel dysfunction in cystic fibrosis. Cell 1993;73:1251-4.

30. Zar H, Saiman L, Quittell L, Prince A. Binding of Pseudomonas aeruginosa to respiratory epithelial cells from patients with various mutations in the cystic fibrosis transmembrane regulator. J Pediatr 1995;126:230-3.

31. Kubesch P, Dork T, Wulbrand U, et al. Genetic determinants of airways' colonisation with Pseudomonas aeruginosa in cystic fibrosis. Lancet 1993:341:189-93.

32. Ramphal R, Pyle M. Evidence for mucins and sialic acid as receptors for Pseudomonas aeruginosa in the lower respiratory tract. Infect Immun 1983;41:339-44.

33. Sajjan U, Reisman J, Doig P, Irvin RT, Forstner G, Forstner J. Binding of nonmucoid Pseudomonas aeruginosa to normal human intestinal mucin and respiratory mucin from patients with cystic fibrosis. J Clin Invest 1992;89:657-65.

34. Reddy MS. Human tracheobronchial mucin: Purification and binding to Pseudomonas aeruginosa. Infect Immun 1992;60:1530-5.

35. Smith JJ, Travis SM, Greenberg P, Welsh MJ. Cystic fibrosis airway epithelia fail to kill bacteria because of abnormal airway surface fluid. Cell 1996;85:229-36.

36. Quinton PM. Viscosity versus composition in airway pathology. Am J Respir Crit Care Med 1994;149:6-7. 
37. Koch C, Hoiby N. Pathogenesis of cystic fibrosis. Lancet 1993;341:1065-74.

38. Speert DP. Host defenses in patients with cystic fibrosis: Modulation by Pseudomonas aeruginosa. Surv Synth Path Res 1985;4:14-33.

39. Wilson R, Sykes DA, Currie D, Cole PJ. Beat frequency of cilia from sites of purulent infection. Thorax 1986;41:453-8.

40. Pier GB, Grout M, Tanweer SZ, et al. Role of mutant CFTR in hypersusceptibility of cystic fibrosis patients to lung infections. Science 1996;271:64-7.

41. Fleiszig SM, Zaidi TS, Pier GB. Pseudomonas aeruginosa invasion of and multiplication with corneal epithelial cells in vitro. Infect Immun 1995;63:4072-7.

42. Barghouthi S, Everett KD, Speert DP. Nonopsonic phagocytosis of Pseudomonas aeruginosa requires facilitated transport of D-glucose by macrophages. J Immunol 1995;154:3420-8.

43. Regelmann WE, Elliott GR, Warwick WJ, Clawson CC. Reduction of sputum Pseudomonas aeruginosa density by antibiotics improves lung function in cystic fibrosis more than do bronchodilators and chest physiotherapy alone. Am Rev Respir Dis 1990;141:914-21.
44. Grimwood K, To M, Semple RA, Rabin HR, Sokol PA, Woods DE. Elevated exoenzyme expression by Pseudomonas aeruginosa is correlated with exacerbations of lung disease in cystic fibrosis. Pediatr Pulmonol 1993;15:135-9.

45. Grimwood K, To M, Rabin H, Woods DE. Inhibition of Pseudomonas aeruginosa exoenzyme expression by subinhibitory antibiotic concentrations. Antimicrob Agents Chemother 1989;33:41-7.

46. Geers TA, Baker NR. The effect of sublethal levels of antibiotics on the pathogenicity of Pseudomonas aeruginosa for tracheal tissue. J Antimicrob Chemother 1987;19:569-78.

47. Cantin A, Woods DE. Protection by antibiotics against myeloperoxidase-dependent cytotoxicity to lung epithelial cells in vitro. J Clin Invest 1993;91:38-45.

48. Howard M, Frizzel RA, Bedwell DM. Aminoglycoside antibiotics restore CFTR function by overcoming premature stop mutations. Nature Med 1996;2:467-9.

49. Ramsey BW. Management of pulmonary disease in patients with cystic fibrosis. N Engl J Med 1996;335:179-88.

50. Moss RB. Cystic fibrosis: pathogenesis, pulmonary infection, and treatment. Clin Infect Dis 1995;21:839-51. 


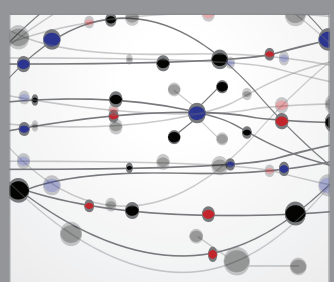

The Scientific World Journal
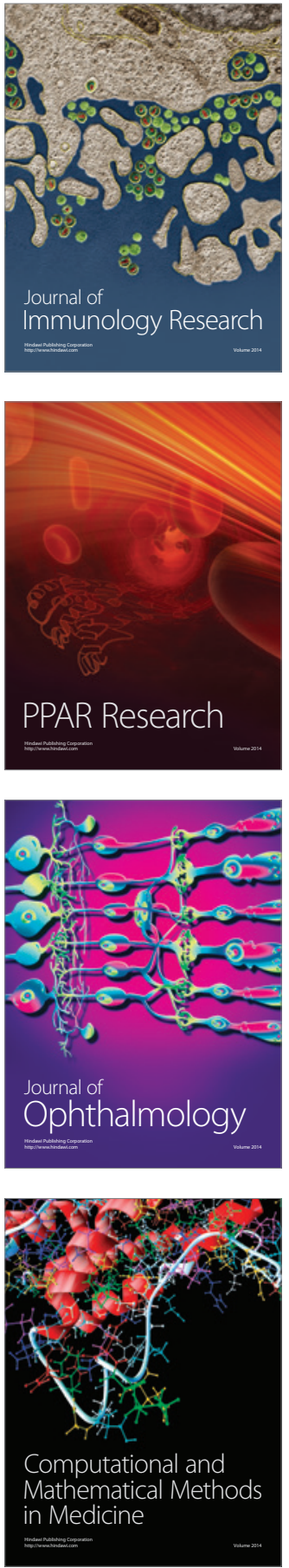

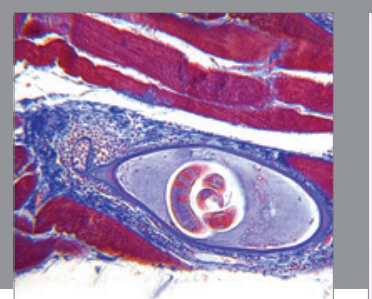

Gastroenterology Research and Practice

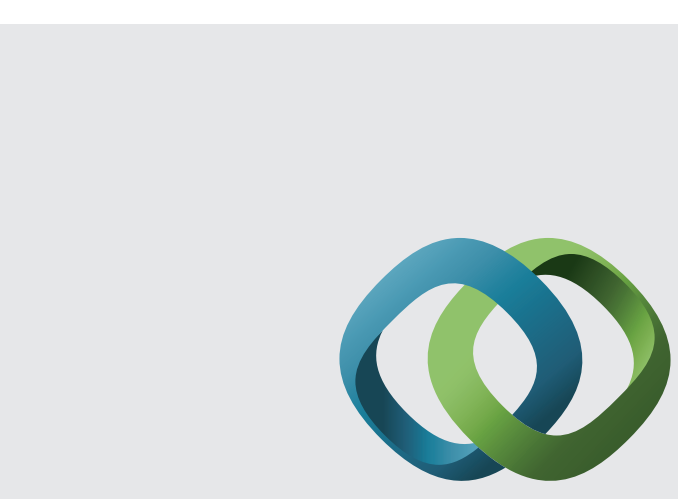

\section{Hindawi}

Submit your manuscripts at

http://www.hindawi.com
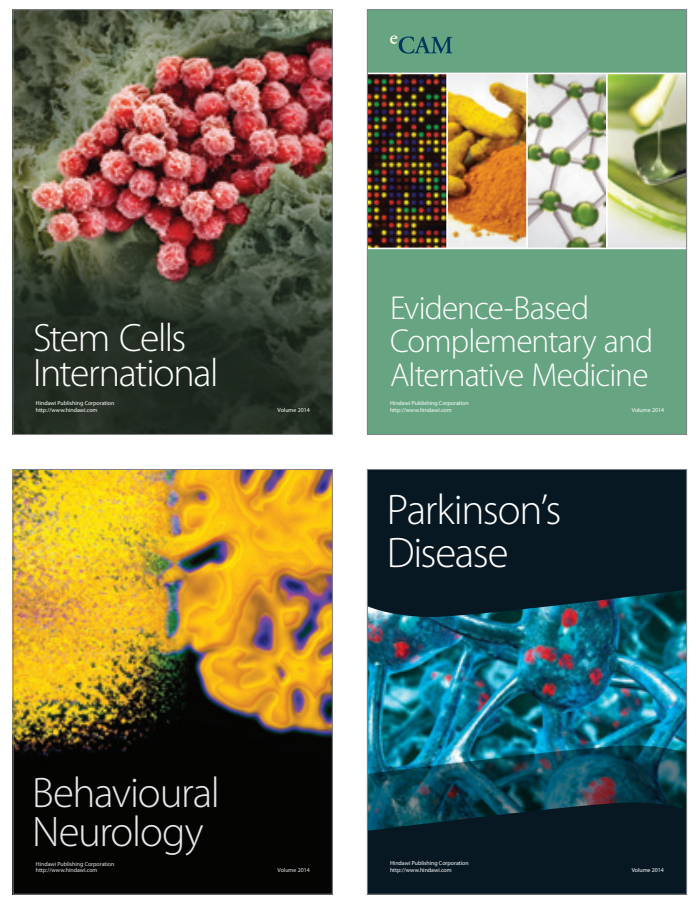
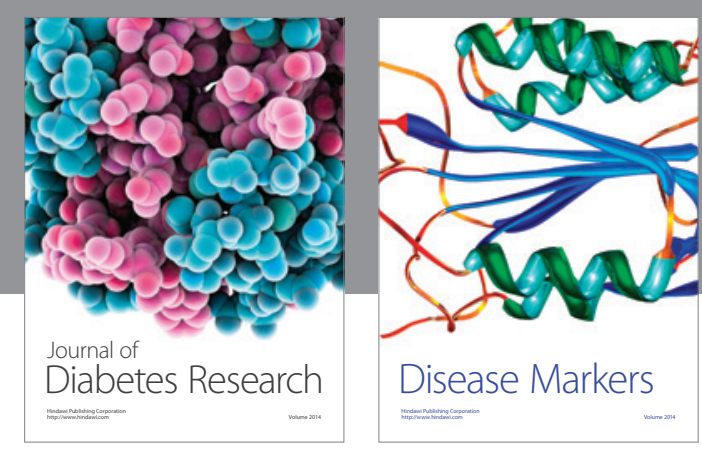

Disease Markers
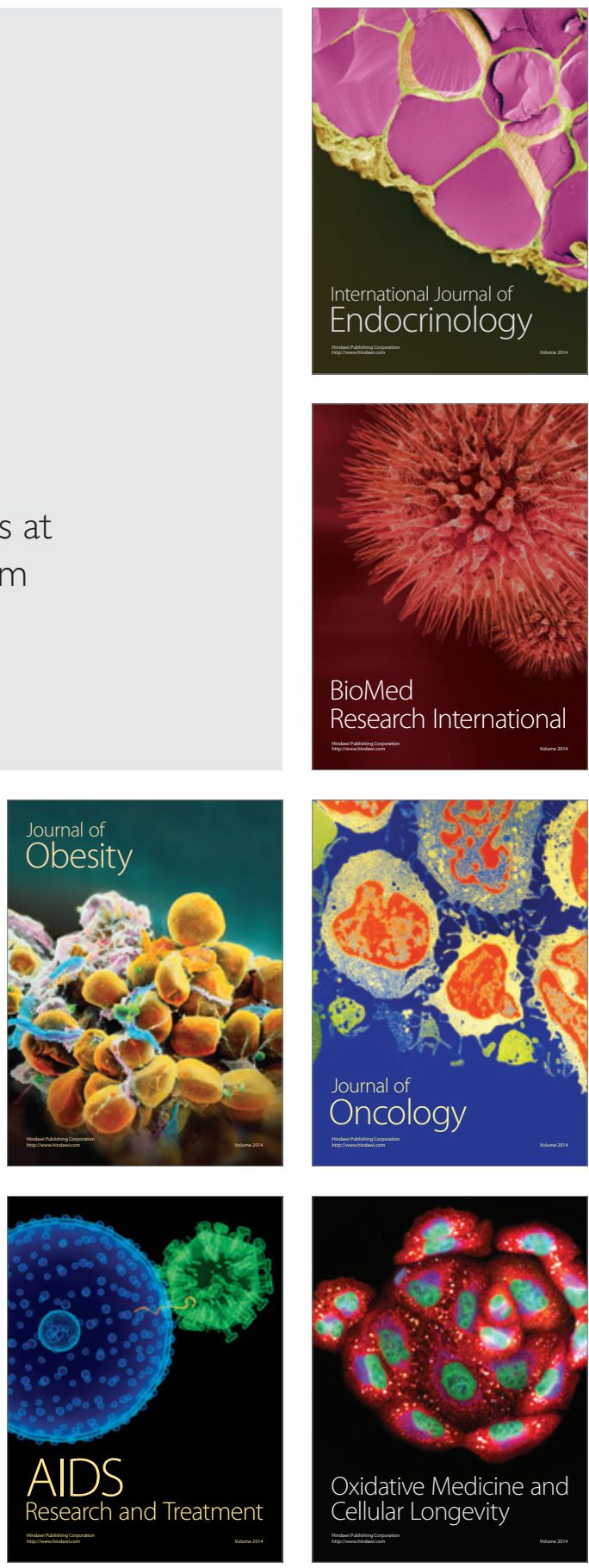